\title{
US Medicare billing info goes public
}

$\mathrm{G}$ overnment measures to publicize medicare payments to health providers in the United States are yielding insights into health system inefficiencies and potential fraud, according to analysts digging through records.

The 2012 data were released Apr. 9 by the Centers for Medicare and Medicaid Services (CMS) after decades of litigation and over the objections of the American Medical Association. The CMS says the data make it possible to conduct a wide range of analyses comparing 6000 different types of services and procedures provided to Medicare beneficiaries. In 2012, US\$77 billion was paid to 880000 providers.

In a blog posting before the data release, Jonathan Blum, CMS's principal deputy administrator, said that the goal was to "shine a light on how care is delivered in the Medicare program" and "help consumers compare the services provided and payments received by individual health care providers. Businesses and consumers alike can use these data to drive decision-making and reward quality, cost-effective care." Blum noted that CMS weighed the privacy interests of physicians against the public's interest in shedding light on government activities and "determined that the public's interest outweighs the privacy interests."

In a statement following the CMS data release, the American Medical Association wrote that "the broad data dump" had "significant shortcomings regarding the accuracy and value of the medical services rendered by physicians. Releasing the data without context will likely lead to inaccuracies, misinterpretations, false conclusions and other unintended consequences."

Dr. Farzad Mostashari, a visiting fellow of the Engelberg Center for Health Care Reform at Brookings Institution in Washington, DC, who served until last October as the Obama administration's top health information technology czar, says the data are already revealing progressively more powerful insights. "By opening this data to the public the government is enabling citizens to help it investigate health system inefficiencies."

By way of example, Mostashari says

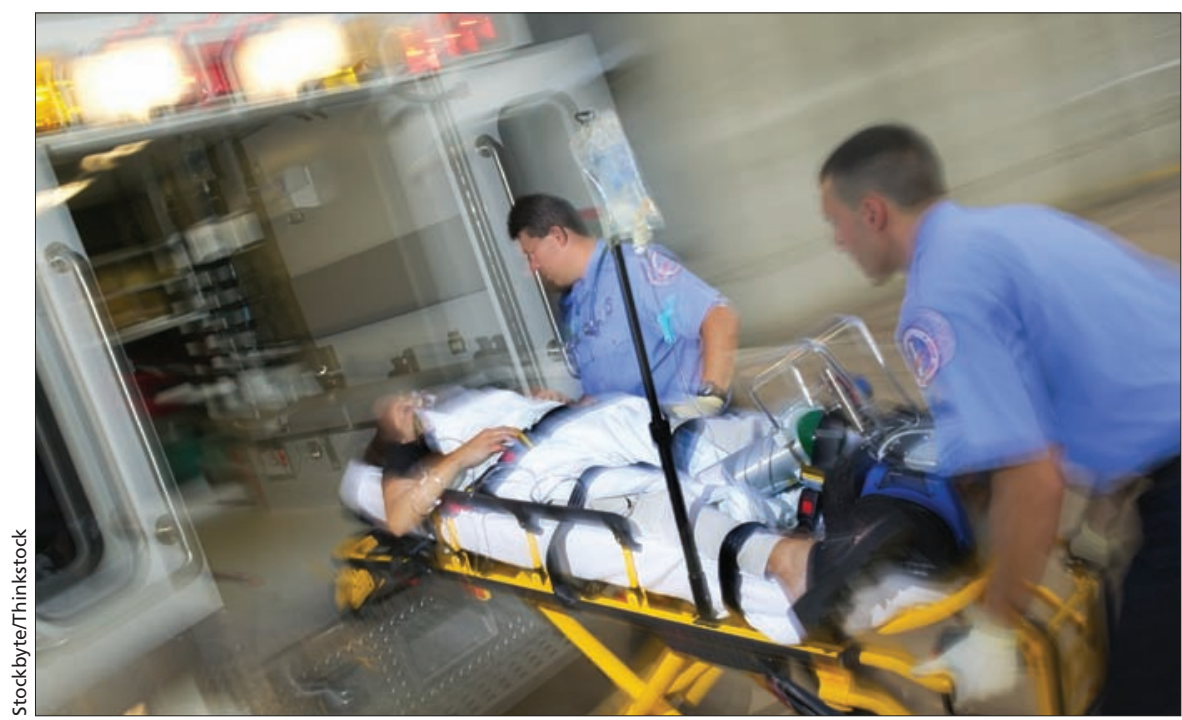

The data reveal that an ambulance company billed Medicare US\$1.15 million in 2012 to move just 26 patients more than 5000 times.

his research has revealed that a New Jersey ambulance company billed Medicare US\$1.15 million in 2012 to move just 26 patients more than 5000 times. Such revelations about the possible misallocation of public health dollars are but one example of the data's usefulness, says Mostashari. "In the near future we're going to see the CMS physicianbilling data matched up with numerous other datasets that are also about to be made public."

One such dataset, to be released in September, will publicly report payments greater than $\$ 10$ to physicians and teaching hospitals from pharmaceutical and medical device companies. Under the Physician Payments Sunshine Act, US doctors must now report any payments or gifts from the pharmaceutical industry.

By comparing the forthcoming data on physicians' commercial links with the recently released CMS billing data, "we'll likely learn a lot about physician prescribing patterns," says Mostashari.

Dr. Daniel Carlat, director, Pew Pres cription Project at Pew Charitable Trusts in Washington, DC, says that the new disclosures are all about "uncovering incentives for physicians to make certain decisions." Publication of physicians' income from industry sources makes them more cautious. These payments, "decrease in proportion to publicity about them."
Richard Saver, a professor of law and health policy at the University of North Carolina, in Chapel Hill, agrees the CMS data, coupled with forthcoming data to be released under the Sunshine Act, will be very helpful to investigators of fraud, "and it could also be useful to health system architects and regulators." The new data will also help illuminate how new technology is used and reveal geographic variations in the intensity of health service delivery, he adds.

Dr. Andrew Boozary, a visiting scientist at the Harvard School of Public Health and codirector of Open Pharma, a Canadian group dedicated to promoting financial transparency, says initiatives such as this are almost nonexistent in Canada. "There is a case for the federal government to step in with legislation forcing transparency of interactions" between commercial entities and physicians, he says.

The provinces could also use their control over drug purchasing to force drug makers to reveal their payments to physicians, he adds. "We are calling on the Ontario Ministry of Health to make disclosures of payments to doctors compulsory for any pharma companies with drugs listed on the Ontario Drug Benefit Program." - Paul Christopher Webster, Toronto, Ont.

CMAJ 2014. DOI:10.1503/cmaj.109-4793 